\title{
Cartografia geomorfológica e a compartimentação das formas do relevo em área de manancial Periurbano na borda Nordeste da bacia sedimentar do Paraná
}

\author{
Geomorphological Cartography and the Landform Compartmentation in \\ Peri-urban Water Springs at the Northeast Border of the Paraná \\ Sedimentary Basin \\ Carlos Wilmer Costa ${ }^{1}$ \\ Reinaldo Lorandi ${ }^{2}$ \\ Thomaz Alvisi de Oliveira ${ }^{3}$ \\ José Augusto de Lollo ${ }^{4}$
}

Recebido em novembro de 2017.

Aprovado em setembro de 2018.

\begin{abstract}
RESUMO
Estudos geomorfológicos em bacias hidrográficas são abundantes, porém, poucos são voltados para bacias periurbanas em que a produção de água é um serviço ecossistêmico relevante e de interesse público. $\mathrm{Na}$ bacia hidrográfica do Ribeirão do Feijão $\left(243,16 \mathrm{~km}^{2}\right)$, localizada na região central do Estado de São Paulo, entre as coordenadas geográficas $22^{\circ} 02^{\prime} 4$ ", $22^{\circ} 13^{\prime} 14^{\prime \prime}$ S e $47^{\circ} 42^{\prime} 46^{\prime \prime}, 47^{\circ} 54^{\prime} 14^{\prime \prime}$ W, a qual foi esculpida em terrenos sedimentares da Bacia Sedimentar do Paraná, um grande volume de água pode deixar de infiltrar e recarregar aquíferos e nascentes, em decorrência de significativa degradação ambiental oriunda do uso incorreto do solo. $\mathrm{Na}$ perspectiva do planejamento territorial, é patente a necessidade de estudos que compartimentem a bacia em unidades menores para que se possa verificar áreas de maior alteração das condições naturais. Diante disso, o objetivo deste trabalho é estabelecer a compartimentação geomorfológica, em escala de 1:50.000, e a integração de informações geoambientais variadas a fim de subsidiar possíveis tomadas de decisão na bacia. Os procedimentos fundamentaram-se na proposta de Ross (1992). A compartimentação das unidades geomorfológicas foi produto de modelagem
\end{abstract}

\footnotetext{
${ }_{1}$ Programa de Pós-graduação em Engenharia Sanitária e Ambiental, Universidade Federal do Rio Grande do Norte, BR - 101, Campus Universitário, Natal, RN CEP 59078-970, Brasil. E-mail: carloswilmercosta@gmail.com

2 Programa de Pós-graduação em Ciências Ambientais, Universidade Federal de São Carlos, Brasil. Email: lorandir@gmail.com

${ }^{3}$ Instituto Federal de Educação, Ciência e Tecnologia do Sul de Minas Gerais, Avenida Dirce Pereira Rosa, 300, Jardim Esperança - Poços de Caldas - MG - CEP 37713-100, Brasil. E-mail: thomaz.oliveira@ifsuldeminas.edu.br

${ }^{4}$ Programa de Pós-graduação em Engenharia Civil, Universidade Estadual Paulista Júlio de Mesquita Filho, Alameda Bahia, 550, CEP 15385-000, Ilha Solteira-SP, Brasil. E-mail: jose.lollo@unesp.br
} 
tridimensional realizada em ambiente de Sistemas de Informações Geográficas (SIG) a partir da sobreposição do Modelo Digital de Elevação (MDE), o relevo sombreado, declividades, tipos de solos e rochas. Foram identificados diferentes níveis taxonômicos, o mais representativo ocorre no $4^{\circ}$ táxon, onde foram identificadas nove unidades de formas do relevo específicas para a bacia. As maiores alterações nas condições morfogênicas naturais da bacia, são ilustradas pelas ravinas e voçorocas identificadas no $6^{\circ}$ táxon, que ocorrem no domínio dos Morros Areno-Argilosos de Topos Convexos Altos. É nesta forma do relevo que estão concentradas o maior número de nascentes, o que expressa a prioridade de contingenciamento dos processos erosivos acelerados nesta área.

PALAVRAS-CHAVE: Bacia hidrográfica. Formas do Relevo. Geoprocessamento. Serviģos Ecossistêmicos. São Carlos.

\begin{abstract}
Several are the geomorphologic studies in water basins; however, few are aimed at peri-urban basins where the water production is a relevant ecosystem service of public interest. In Ribeirão do Feijão basin $\left(243.16 \mathrm{~km}^{2}\right)$, located in central area of the state of São Paulo, between co-ordinates $22^{\circ} 02^{\prime} 4^{\prime \prime}, 22^{\circ} 13^{\prime} 14^{\prime \prime} \mathrm{S}$ and $47^{\circ} 42^{\prime} 46^{\prime \prime}, 47^{\circ} 54^{\prime} 14^{\prime \prime} \mathrm{W}$, sculpted in sedimentary terrains of the Paraná Sedimentary Basin, a considerable volume of water can infiltrate impairing the recharge of the aquifer and water springs, due to extensive environmental degradation caused by incorrect land use. From the perspective of land planning, studies where the basin is split in smaller units are essential to verify areas where the alteration in natural conditions is significant. This study is aimed at establishing a geomorphological subdivision, in a scale of 1:50.000, and the integration of varied geoenvironmental information in order to subsidize possible decision making processes in the basin. The procedures to substantiate the proposed Ross (1992). The compartmentalization of geomorphological units was carried in three-dimensional environment in a geographic information system (GIS) using geographic overlapping of the Digital Elevation Model (DEM), Hillshade, steepness, rock types and soils. To do so, different taxonomic levels were identified. In the fourth taxon, nine terrain units were identified. The greatest alterations in the natural morphogenic conditions are illustrated by the ravines and gullies (sixth taxon), which occurs in the domain of Sandy-clay Hills of High Convex Summits. It is in this landform that we find the highest number of springs, expressing the priority of contingency of accelerated erosive processes in the area.
\end{abstract}

KEYWORDS: Watershed. Relief. Forms. Geoprocessing. Ecosystem Services. São Carlos.

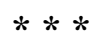

\title{
Introdução
}

Um planejamento territorial adequado, exige a aquisição de conhecimentos básicos a respeito do meio físico em que se realizam as atividades humanas responsáveis pelo desenvolvimento sócioeconômico. 
Entre tais conhecimentos a geomorfologia tem relevância, uma vez que, são os processos que se desdobram sobre as formas que definem e moldam a superfície, apresentando consequentemente, cenários de maior ou menor comprometimento ambiental. Sob esse prisma a compartimentação de terrenos assume destaque (PONÇANO et al., 1981) e deve ir além das descrição e representação das formas superficiais, oferecendo a oportunidade de visualização e compreensão da atuação dos processos morfogenéticos e de suas implicações ambientais (BISHOP et al., 2012).

O relevo assume papel fundamental nas análises voltadas ao planejamento territorial e ao uso adequado do solo (CASTALDI e CHIOCCHINI, 2012), pois, pode se apresentar altamente instável face aos processos da natureza e pela ação antrópica (ROSS, 2006). Não obstante, as atividades humanas necessitam espaços territoriais cada vez maiores para serem implementadas, os quais são definidos em acordo com as características do substrato e pelas das formas da superfície.

Em bacias hidrográficas, terrenos com morfologias homogêneas indicam processos e comportamentos hidráulicos peculiares em função da presença concomitante de tipos de rochas, solos e demais atributos ambientais.

Nesse âmbito, o relevo se destaca como subsistema que contribui por meio de sua organização para a dinâmica das águas na bacia, em superfície e em sub-superfície (CERMINARO e OLIVEIRA, 2015).

Neste caso, no tocante ao planejamento territorial integrado ao hídrico, o mapeamento geomorfológico deve servir, acima de tudo, para o estabelecimento de diretrizes específicas para cada uma das formas semelhantes do relevo cartografadas, pois representam de maneira concentrada importantes processos de formação da superfície terrestre e refletem distintos graus de potencialidades e de fragilidades ambientais.

A bacia do Ribeirão do Feijão é a principal fonte de água superficial da cidade de São Carlos - SP (225.681 habitantes) (SEADE, 2017), de onde 
provém aproximadamente $27 \% \quad(246,3 \mathrm{~L} / \mathrm{s})$ do abastecimento do município/cidade (COSTA et al., 2013).

Concomitantemente a essa situação, ocorre em grande parte da bacia afloramentos da Formação Botucatu (ZUQUETTE, 1981 e NISHIYAMA, 1991), principal unidade geológica que compõe o Sistema Aquífero Guarani (SAG) (DAEE, 1974), a mais importante unidade hidrogeológica da América do Sul. Entretanto, o manancial em apreço está localizado na zona periurbana da cidade de São Carlos, e o equilíbrio natural do ambiente tem sido desestabilizado por meio da constante implantação de atividades sem o devido planejamento e a adoção de critérios técnicos.

A legislação local vigente, que institui as APREM-SC (Áreas de Proteção e Recuperação dos Mananciais do Município de São Carlos, Lei No 13.944) (SÃO CARLOS, 2006) e a Área de Preservação Ambiental de Corumbataí (Decreto Estadual n²0.960, de 8 de junho de 1983), adotam a bacia como unidade de planejamento territorial e expressam a obrigação de conservação dos recursos hídricos, porém, não especificam quais áreas devem ser protegidas ou recuperadas em função das suas fragilidades e potencialidades.

Nesse contexto, abre-se aqui uma oportunidade para que os dados e a compartimentação ora apresentados possam subsidiar tal avaliação.

Em se tratando de um estudo realizado em uma bacia em que a produção de água é um serviço ecossistêmico relevante e de interesse público, têm-se como objetivo deste trabalho o mapeamento das formas do relevo, em escala de 1:50.000, e sua relação com outros processos geoambientais, como o de escoamento de superfície, os processos erosivos acelerados e a contaminação das águas subterrâneas. 


\section{Fisiografia da área de estudo}

\section{Conforme demonstrado na}

Fig, a bacia hidrográfica do Ribeirão do Feijão engloba parte dos municípios de São Carlos, Itirapina e Analândia, sendo que o principal centro urbano regional é a cidade de São Carlos (SP).

Figura 1 - Localização e unidades geológicas.
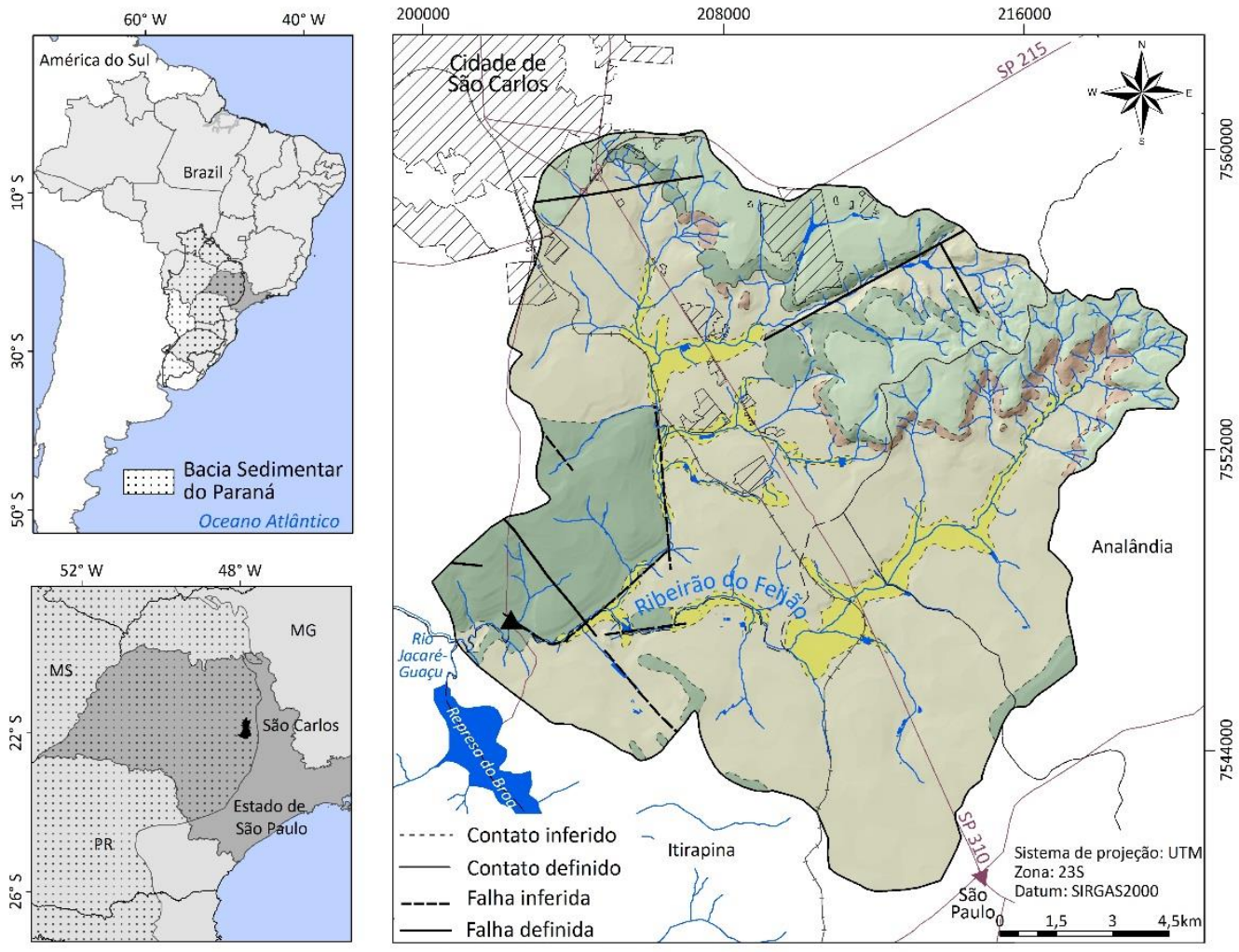

VII Área urbanizada de São Carlos

_. - Limites municipais

_ Principais rodovias

$\longrightarrow$ Ferrovia

- Captação de água superficial

- Elementos hídricos

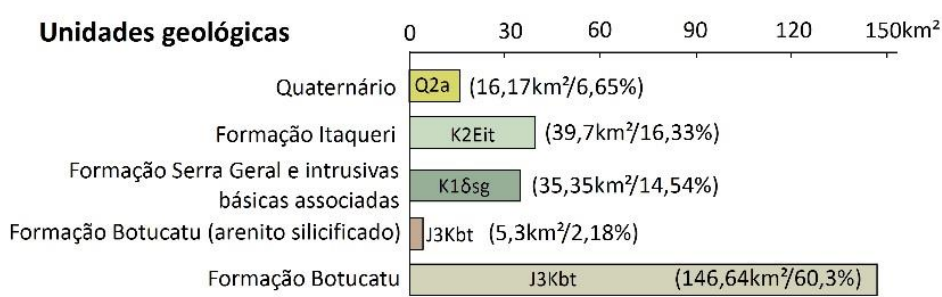

Fonte: adaptado de Zuquette (1981) e Nishiyama (1991).

A partir da confluência com o ribeirão do Lobo, o Ribeirão do Feijão a forma o Rio Jacaré-Guaçu, afluente pela margem direita do Rio Tietê. Este, com caráter consequente em relação às camadas sedimentares da Bacia do 
Paraná, escoa o Estado de São Paulo no sentido sudeste-noroeste. Por sua vez, o Rio Tietê desemboca no Rio Paraná, que drena a porção meridional do Brasil, a partir da latitude $16^{\circ}$ sul.

A rede de drenagem apresenta padrão dendrítico (CHRISTOFOLETTI, 1974) e a extensão é de $248 \mathrm{~km}$. Os cursos d'água, com base na metodologia proposta por Strahler (1952), distribuem-se da seguinte forma (extensão): $1^{\mathrm{a}}$ ordem somam $137 \mathrm{~km} ; 50,2 \mathrm{~km}$ são de $2^{\mathrm{a}}$ ordem; $23,3 \mathrm{~km}$ de $3^{\mathrm{a}}$ ordem; $30,9 \mathrm{~km}$ de $4^{\mathrm{a}}$ ordem e $6,6 \mathrm{~km}$ de $5^{\mathrm{a}}$ ordem.

Em escala geológica continental, a área estudada localiza-se na Província Estrutural do Paraná, disposta no flanco nordeste da Bacia Sedimentar do Paraná. Do ponto de vista litoestratigráfico, são encontrados representantes litológicos que vão da Era Mesozoica até a Cenozoica (ZUQUETTE, 1981; NISHIYAMA, 1991; CPRM, 2006) (Erro! Fonte de referência não encontrada.).

Os solos representam os depósitos residuais ou que tenham sofrido transporte, resultante do intemperismo de arenitos, argilitos, basaltos e magmatitos básicos, sendo diferenciados quanto às seguintes características geotécnicas: espessura, textura, composição mineralógica e permeabilidade (NISHIYAMA, 1991) (Erro! Fonte de referência não encontrada.).

Segundo a classificação climática de Köppen, o clima encontra-se no limiar entre as classificações Cwa.i e Aw.i., caracterizado pelo clima tropical com verão úmido e inverno seco (TOLENTINO, 2007).

A floresta tropical semidecídua e a de galeria são as fisionomias predominantes, seguidas do cerrado (cerrado sensu stricto, capoeiras e campos úmidos) (SOARES, SILVA e LIMA, 2003). Também há presença de áreas de florestas regeneradas que se desenvolveram em áreas outrora ocupadas com atividades agropecuárias.

Nos dias atuais, a vegetação nativa encontra-se bastante fragmentada, principalmente, devido à interferência das atividades humanas. Essas áreas, antes florestadas, cederam lugar a cana-de-açúcar, citricultura, pecuária e silvicultura. 
Tabela 1 - Unidades geológicas.

\begin{tabular}{|c|c|c|}
\hline Unidades & Período & Características \\
\hline $\begin{array}{l}\text { Quaternário } \\
\text { (aliviões e } \\
\text { coluviões) }\end{array}$ & Quaternário & $\begin{array}{c}\text { É representado por amplas planícies que ocorrem ao longo } \\
\text { dos fundos de vale do Ribeirão do Feijão e afluentes. São } \\
\text { constituídas por sedimentos aluvionares e coluvionares de } \\
\text { textura arenosa devido à contribuição das litologias } \\
\text { adjacentes. }\end{array}$ \\
\hline $\begin{array}{l}\text { Formação } \\
\text { Itaqueri }\end{array}$ & Terciário & $\begin{array}{l}\text { É composta por arenitos não cimentados, de granulometria } \\
\text { fina a grosseira, com matriz argilosa e/ou siltosa, arenitos } \\
\text { conglomeráticos, argilitos e conglomerados. É representada } \\
\text { por cobertura sedimentar pós-basáltica encontrando-se } \\
\text { assentados sobre as litologias das formações Serra Geral e } \\
\text { Botucatu. Ocupa as superfícies de cimeira no reverso das } \\
\text { cuestas atingindo cerca de } 60 \mathrm{~m} \text { de espessura. }\end{array}$ \\
\hline $\begin{array}{l}\text { Formação } \\
\text { Serra Geral e } \\
\text { Intrusivas } \\
\text { básicas }\end{array}$ & Cretáceo & $\begin{array}{c}\text { Constitui-se de sequências de derrames de lavas basálticas } \\
\text { e diques e sills de diabásio, apresentando-se intensamente } \\
\text { fraturados, aspecto denso e textura afanítica. Encontra-se } \\
\text { assentada sobre os arenitos da Formação Botucatu, com } \\
\text { espessura máxima de } 80 \text { metros. }\end{array}$ \\
\hline $\begin{array}{l}\text { Formação } \\
\text { Botucatu }\end{array}$ & \multirow[t]{2}{*}{$\begin{array}{l}\text { Cretáceo } \\
\text { Jurássico }\end{array}$} & $\begin{array}{l}\text { Constituída predominantemente por arenitos eólicos } \\
\text { atribuídos a depósitos em ambiente desértico, com } \\
\text { granulação fina a média, partículas bem arredondadas e } \\
\text { composição essencialmente quartzosa ( } 80 \% \text { ), a espessura } \\
\text { varia entre } 20 \text { e } 280 \text { metros. De acordo com Portillo (1988) } \\
\text { Apresenta grande quantidade de poros interconectados e } \\
\text { uma elevada capacidade de armazenar e fornecer água. } \\
\text { Segundo Iritani e Ezaki (2012) é o principal formador do } \\
\text { Aquífero Guarani. }\end{array}$ \\
\hline $\begin{array}{l}\text { Arenitos } \\
\text { silificados da } \\
\text { Formação } \\
\text { Botucatu }\end{array}$ & & $\begin{array}{l}\text { Encontram-se subjacente ao basalto da Formação Serra } \\
\text { Geral. Sustentam escarpas verticais na forma de Cuestas } \\
\text { com desníveis topográficos entre } 60 \text { e } 120 \text { metros. Segundo } \\
\text { (Paraguassu, 1972) a silicificação dos arenitos Botucatu é } \\
\text { um processo resultante da precipitação de sílica a partir da } \\
\text { água subterrânea. }\end{array}$ \\
\hline
\end{tabular}

Fonte: Zuquette (1981); Nishiyama (1991); CPRM (2006).

Neste processo investigativo, a compartimentação do modelado em níveis taxonômicos passou pela identificação das diferentes dimensões do relevo, das feições maiores para as menores, chegando ao nível de segmentos das vertentes e dos processos geodinâmicos. Os procedimentos metodológicos fundamentaram-se na proposta de Ross (1992). 
Tabela 2 - Características geotécnicas dos solos. Fonte: Nishiyama (1991).

\begin{tabular}{|c|c|c|c|c|c|c|c|c|c|}
\hline \multirow{2}{*}{\multicolumn{2}{|c|}{ Solos }} & \multirow{2}{*}{$\begin{array}{c}\text { Espessura } \\
\text { (metros) }\end{array}$} & \multicolumn{6}{|c|}{ Granulometria média (\%) } & \multirow{2}{*}{$\begin{array}{c}\mathbf{K} \\
(\mathrm{cm} / \mathrm{s})\end{array}$} \\
\hline & & & ${ }^{*} \mathrm{Ar}$ & $\mathrm{Si}$ & Af & $\mathrm{Am}$ & $\mathrm{Ag}$ & G & \\
\hline \multirow{3}{*}{ 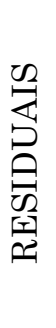 } & Formação Botucatu & 2 a 20 & 7 & 5 & 77 & 10 & 1 & - & $10^{-3}$ a $10^{-2}$ \\
\hline & $\begin{array}{c}\text { Formação Serra } \\
\text { Geral e intrusivas } \\
\text { básicas }\end{array}$ & 2 a 10 & 36 & 35 & 24 & 4 & 1 & - & $10^{-6}$ a $10^{-3}$ \\
\hline & Formação Itaqueri & 10 a 20 & 35 & 20 & 38 & 6 & 1 & - & $10^{-6}$ a $10^{-2}$ \\
\hline \multirow{6}{*}{ 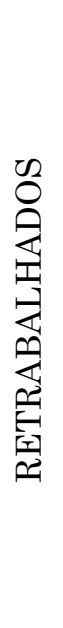 } & Arenoso I & 10 a 20 & 13 & 4 & 66 & 16 & 1 & - & \multirow{3}{*}{$10^{-3}$ a $10^{-2}$} \\
\hline & Arenoso III & 10 & 38 & 14 & 41 & 7 & - & - & \\
\hline & Arenoso IV & 10 a 20 & 10 & 4 & 76 & 6 & 3 & 1 & \\
\hline & Misto & 10 a 20 & 25 & 2 & 42 & 6 & 25 & - & $10^{-4}$ a $10^{-2}$ \\
\hline & $\begin{array}{c}* * \text { Concreções } \\
\text { Lateríticas }\end{array}$ & 10 & 60 & 10 & 10 & & 20 & & \\
\hline & Sedimentos aluviais & 0 a 10 & \multicolumn{6}{|c|}{ Arenoso } & $10^{-4}$ a $10^{-3}$ \\
\hline
\end{tabular}

*Ar: argila, Si: Silte, Af: areia fina, Am: areia média, Ag: areia grossa, G: pedregulho; k: coeficiente de permeabilidade.

**De acordo com unidades pedológicas correspondentes (OLIVEIRA ePRADO, 1984).

Fonte: Nishiyama (1991).

Fontes primárias e secundárias embasaram as discussões teóricas e forneceram informações atinentes aos contextos morfométrico/morfográfico, litoestrutural, de uso da terra, hidrológico e hidrogeológico (Tabela 3).

O software de geoprocessamento ArcGIS $^{\circledR}$ 10.4.1 (ESRI, 2016) possibilitou a montagem e manipulação do banco de dados.

Para o georreferenciamento dos cartogramas na Zona 23S, foi adotado o Sistema de Referência Geocêntrico para as Américas SIRGAS2000 (IBGE, 2005) e o sistema de projeção e de coordenadas UTM. 
Conforme ilustrado na Erro! Fonte de referência não encontrada., a abordagem empregada consistiu em várias etapas, a saber:

Tabela 3 - Documentos cartográficos utilizados.

\begin{tabular}{|c|c|c|c|c|}
\hline & Atributos & Descrição & Fontes & Escala \\
\hline & Rochas & $\begin{array}{c}\text { Mapas } \\
\text { geológicos }\end{array}$ & $\begin{array}{c}\text { Zuquette (1981), } \\
\text { Nishiyama (1991), } \\
\text { Folha Geológica de } \\
\text { Corumbataí (IG, 1984) }\end{array}$ & \multirow{5}{*}{$1: 50.000$} \\
\hline & Solos & Materiais inconsolidados & Nishiyama (1991) & \\
\hline \multirow{2}{*}{\multicolumn{2}{|c|}{ Relevo }} & Formas de Terreno & TOPODATA (INPE, 2017) & \\
\hline & & Declividades & \multirow{2}{*}{$\begin{array}{l}\text { Folhas Topográficas (IBGE, } \\
\text { 1971): } \\
\text { São Carlos - SF-23-Y-A-I-1 } \\
\text { Corumbataí - SF-23-Y-A-I- } \\
2\end{array}$} & \\
\hline & $\begin{array}{l}\text { Elementos } \\
\text { hídricos }\end{array}$ & $\begin{array}{c}\text { Rios, lagos e } \\
\text { reservatórios artificiais }\end{array}$ & & \\
\hline & $\begin{array}{c}\text { Cobertura } \\
\text { e uso do solo }\end{array}$ & $\begin{array}{l}\text { Cobertura vegetal } \\
\text { e atividades antrópicas }\end{array}$ & $\begin{array}{c}\text { Imagens do satélite } \\
\text { GeoEye de } 2011 \\
\text { Resolução de 0,5m (ESRI, } \\
\text { 2011) }\end{array}$ & - \\
\hline \multirow{3}{*}{ 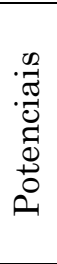 } & $\begin{array}{l}\text { Escoamento } \\
\text { superficial }\end{array}$ & Escoamento de superfície & \multirow{3}{*}{ Costa (2017) } & \multirow{3}{*}{$1: 50.000$} \\
\hline & $\begin{array}{c}\text { Erosão } \\
\text { acelerada }\end{array}$ & $\begin{array}{c}\text { Processos } \\
\text { Erosivos lineares } \\
\end{array}$ & & \\
\hline & $\begin{array}{c}\text { Contaminação } \\
\text { de aquíferos }\end{array}$ & $\begin{array}{c}\text { Contaminação das águas } \\
\text { subterrâneas }\end{array}$ & & \\
\hline
\end{tabular}

1) Compilação de dados existentes para a área de estudo e seleção dos atributos geoambientais que integram do banco de dados;

2) Manipulação e produção de cartogramas em ambiente de Sistemas de Informações Geográficas;

3) Compartimentação e vetorização das formas do relevo;

4) Validação dos produtos cartográficos por meio de trabalhos de campo. 
Figura 2 - Fluxograma do método.

Rev. Bras. de Cartografia, vol. 70, n. 4, outubro/dezembro, 2018. pp. 1257 - 1288. 


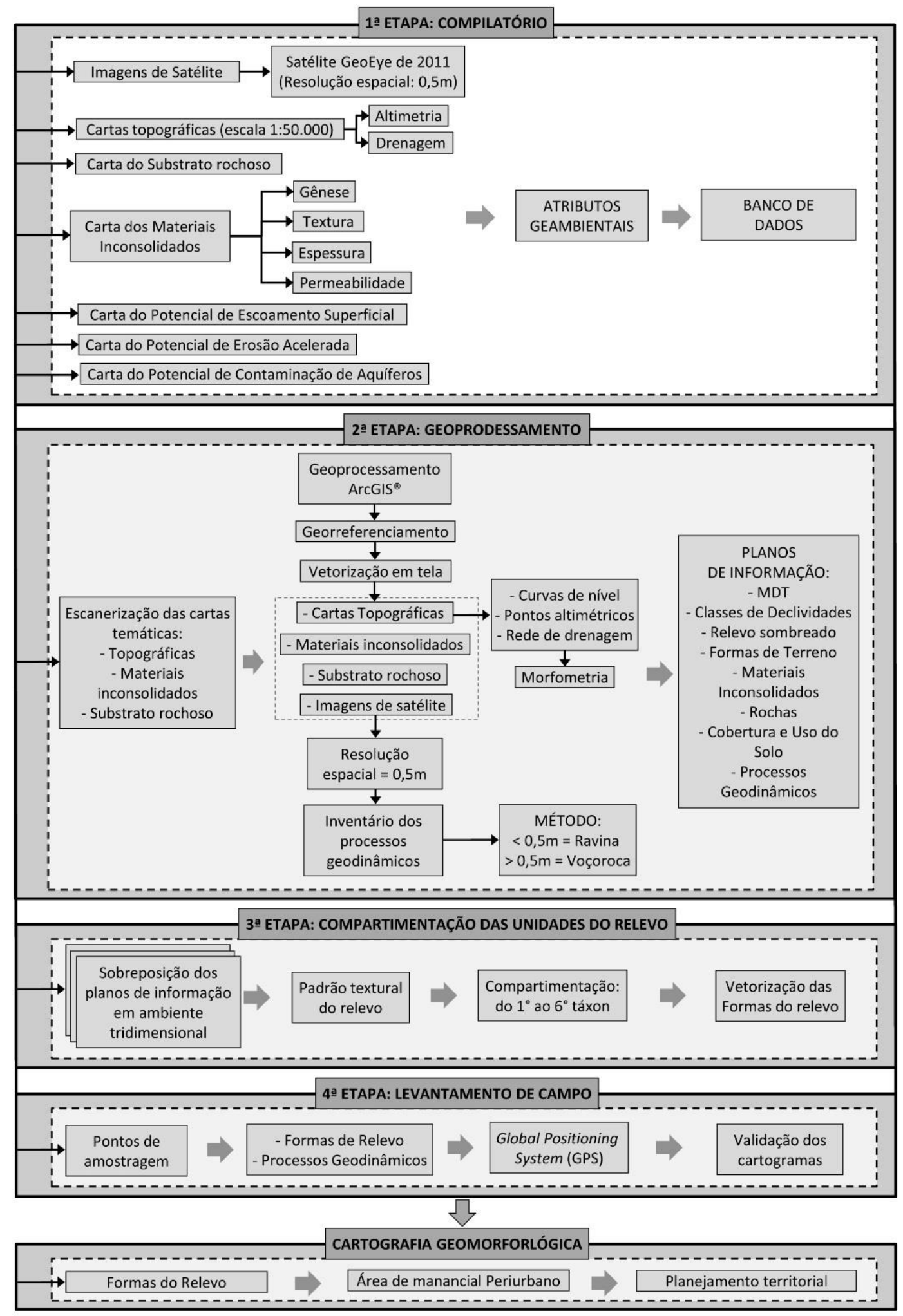

Fonte: Elaborada pelo autor.

Rev. Bras. de Cartografia, vol. 70, n. 4, outubro/dezembro, 2018. pp. 1257 - 1288. 
Foram utilizadas imagens do satélite GeoEye do ano de 2011, com resolução espacial de 0,5m para elaboração do mapa temático de cobertura e uso do solo por meio de classificação e digitalização manual em tela.

As folhas topográficas em escala de 1:50.000 produzidas pelo IBGE constituem uma representação cartográfica de grande importância para o mapeamento geomorfológico e serviram como base de dados para a elaboração do Modelo Digital do Terreno (MDT), do relevo sombreado e da carta de declividades. Neste caso, a estrutura matricial proporcionada pelas folhas topográficas, representada por células com tamanho de 8,61x8,61 metros, resultaram em uma resolução espacial mais acurada, se comparada a estrutura matricial de 30x30 dos dados topográficos da Shuttle Radar Topography Mission (SRTM).

Por se tratar de uma área de manancial periurbano, uma nova concepção de abordagem geomorfológica integrada foi aqui introduzida, somando-se a ela discussões sobre os potenciais de: escoamento superficial, de erosão acelerada e de contaminação de aquíferos. Tais cartogramas foram obtidos no formato digital (shapefile) a partir dos trabalhos realizados na área de estudo por Costa (2017).

Os planos de informação (Materiais Inconsolidados, Classes de Declividades, Cobertura e Uso do Solo, Potencial de Escoamento Superficial, Potencial de Erosão Acelerada e Potencial de Contaminação de Aquíferos) são apresentados na Erro! Fonte de referência não encontrada.

A técnica de sobreposição de mapas em ambiente tridimensional foi a principal ferramenta que auxiliou no reconhecimento e na espacialização das feições superficiais.

O padrão textural do modelado foi apurado com o uso do relevo sombreado. Neste caso, as áreas de maior sombreamento indicaram relevo escarpado, representado por áreas de morros e vertentes dissecadas. Por outro lado, não foi verificada a presença de sombras nas áreas de relevo plano, representado pelas planícies de inundação. 
Figura 3 - Planos de informação.

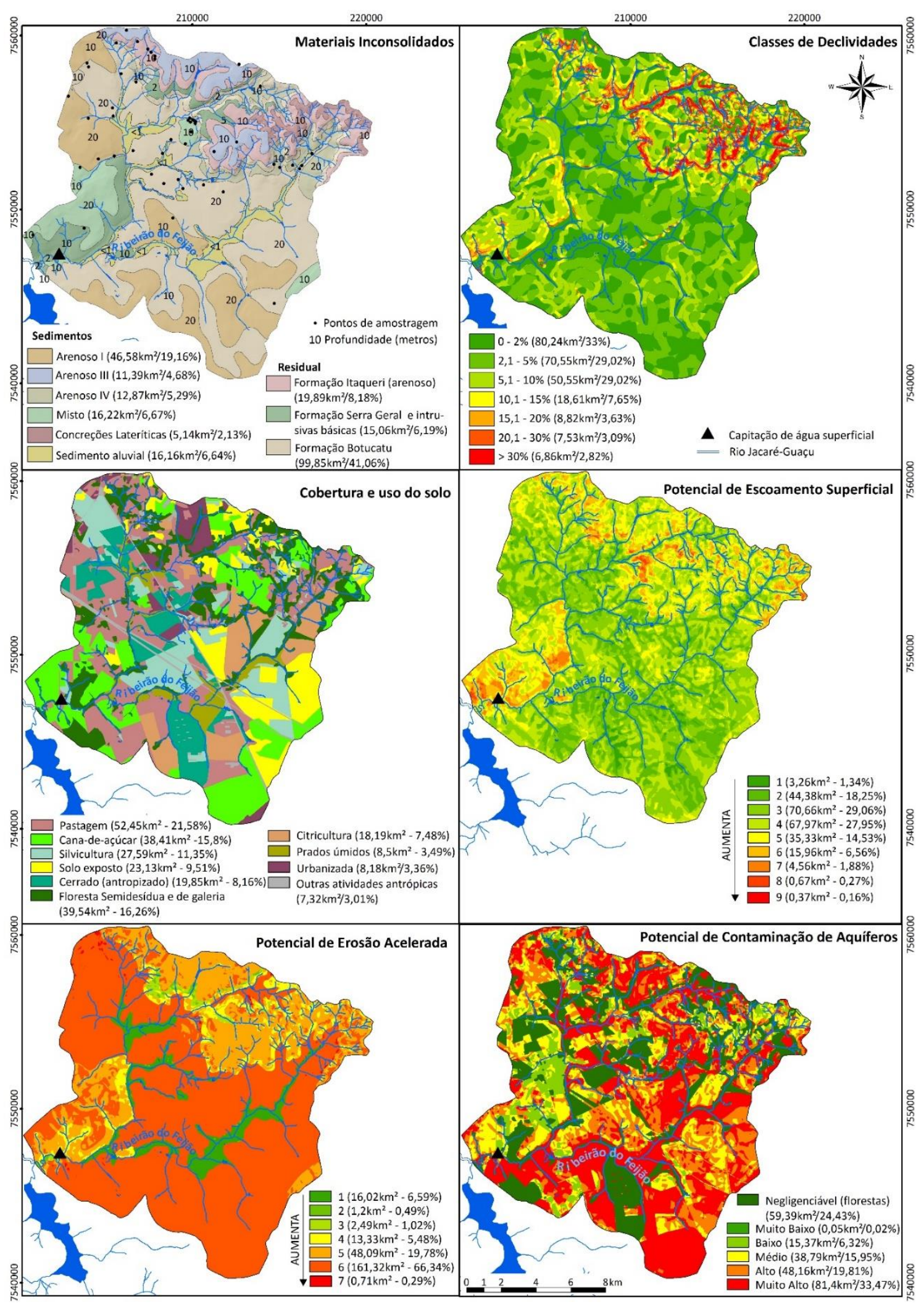

Fonte: Elaborada pelo autor. 
Com relação ao grau de inclinação dos terrenos, verifica-se que as planícies caracterizam-se pela predominância de declividades inferiores a $2 \%$ e convergência espacial com solos aluvionares. As colinas encontram-se dispostas em terrenos suavemente ondulado em que preponderam declividades de 10\%. Nos Morros, as declividades são mais acentuadas (até $30 \%)$. O relevo cuestiforme é marcado por declividades que superam os $30 \%$, dispostas em vertentes abruptas. Nas vertentes escarpadas as inclinações superam os $20 \%$.

Com relação a geologia, levou-se em consideração fatores que notadamente estão associados a sustentação do relevo e refletem na expressão de alteração de suas formas, como a tectônica, o lito-estrutural e o grau de coesão das rochas. Neste caso, rochas básicas da Formação Serra Geral são mais resistentes a denudação se comparadas aos arenitos da Formação Botucatu e Itaqueri.

Possíveis entalhamentos concordantes da rede de drenagem foram verificados a partir da análise do posicionamento e orientação das falhas geológicas.

O estudo sobre o comportamento hidrogeológico e a classificação quanto à porosidade das rochas armazenadoras (intergranulares ou fraturadas) e quanto às características hidráulicas, em livres ou confinados foi realizado com base no trabalho de Costa (2017).

Os materiais inconsolidados (NISHIYAMA, 1991) foram analisados levando em consideração características como a gênese, espessura, textura e a permeabilidade de cada tipo de solo. Essas características refletem uma certa correspondência entre as feições superficiais e o manto de alteração das litologias subjacentes. Segundo Ponçano et al. (1981), os depósitos coluvionares arenosos espessos estão associados a relevos colinosos e suaves, por outro lado, solos com elevada presença de grãos finos (silte e argila) estão associados a relevo de morros e escarpas. Solos superficiais pouco desenvolvidos geralmente se fazem presentes em vertentes escarpadas, com inclinação que superam os $30 \%$. 
Em escala de vertente, os processos geodinâmicos do Holoceno foram cartografados com base na interpretação de imagens de satélite (resolução de $0,5 \mathrm{~m}$ ) e posterior validação in loco. Foram considerados como ravinas, os processos geodinâmicos de até $50 \mathrm{~cm}$ de largura e profundidade. Acima desta metragem foram consideradas voçorocas (IPT, 1989).

Os perfis morfológico-estruturais foram posicionados de modo a abranger todas as formas de relevo e formações geológicas subjacentes. Tais perfis, foram elaborados a partir da análise de transectos espacializados em ambiente 3D.

Quanto a morfometria, as formas de relevo foram quantificadas em função da Matriz de Índices de Dissecação do Relevo a partir das informações altimétricas e da rede de drenagem extraídas das cartas topográficas (Erro! Fonte de referência não encontrada.).

Tabela 4 - Índice de dissecação do relevo.

\begin{tabular}{c|c|c|c|c|c}
\hline \multicolumn{7}{c}{ Matriz dos índices de dissecação do relevo } \\
\hline \multirow{2}{*}{$\begin{array}{c}\text { Graus de } \\
\text { entalhamento } \\
\text { dos vales }\end{array}$} & $\begin{array}{c}\text { Muito } \\
\text { grande (1) }\end{array}$ & Grande (2) & Média (3) & Pequena (4) & $\begin{array}{c}\text { Muito } \\
\text { pequena (5) }\end{array}$ \\
\cline { 2 - 6 } & $>1500 \mathrm{~m}$ & $\begin{array}{c}1500 \text { a } 700 \\
\mathrm{~m}\end{array}$ & 700 a $300 \mathrm{~m}$ & $\begin{array}{c}300 \text { a } 100 \\
\mathrm{~m}\end{array}$ & $<100 \mathrm{~m}$ \\
\hline $\begin{array}{c}\text { Muito Fraco (1) } \\
(<10 \mathrm{~m})\end{array}$ & 11 & 12 & 13 & 14 & 15 \\
\hline $\begin{array}{c}\text { Fraco (2) } \\
(10 \text { a } 20 \mathrm{~m})\end{array}$ & 21 & 22 & 23 & 24 & 25 \\
\hline $\begin{array}{c}\text { Médio (3) } \\
(20 \text { a } 40 \mathrm{~m})\end{array}$ & 31 & 32 & 33 & 34 & 35 \\
\hline $\begin{array}{c}\text { Forte (4) } \\
(40 \text { a } 80 \mathrm{~m})\end{array}$ & 41 & 42 & 43 & 44 & 45 \\
\hline $\begin{array}{c}\text { Muito Forte }(5) \\
(>80 \mathrm{~m})\end{array}$ & 51 & 52 & 53 & 54 & 55 \\
\hline
\end{tabular}

Fonte: Ross (1992). 


\section{Discussão dos resultados}

Em termos de morfoestrutura continental ( $1^{\circ}$ táxon), a área estudada está inserida integralmente na Bacia Sedimentar do Paraná. Esta unidade morfoestrutural, comporta-se como uma complexa fossa intracratônica sinclinal soerguida, com acumulação de rochas sedimentares e vulcânicas, encravada no dorso do escudo pré-cambriano, o qual é composto por rochas ígneas e metamórficas (AB'SÁBER, 1949 e 1954; ALMEIDA, 1964 e MILANI et al., 2007).

Abrangida pela Bacia Sedimentar do Paraná, a unidade morfoescultural Planalto Ocidental Paulista ( $2^{\circ}$ táxon), se estende para noroeste a partir de um ressalto topográfico balizado pelas cuestas areníticobasálticas as quais formam um grande alinhamento (norte-sudoeste) na região central do Estado de São Paulo (ROSS, 1985; ROSS e MOROZ, 1997). O relevo dessa morfoescultura é representado por uma superfície levemente ondulada, extremamente suavizada, com predomínio de colinas amplas e baixas com topos convexados a aplanados; muito favorável às atividades agrícolas (PONÇANO et al., 1981).

Como resultado do processo de circundesnudação pós-cretácea ocorrido na borda oriental da Bacia Sedimentar do Paraná, (AB’SÁBER, 1949, 2003), o Planalto Ocidental Paulista se mostra fragmentado (ROSS e MOROZ, 1997) sendo possível delimitar duas sub-unidades morfológicas na bacia hidrográfica do Ribeirão do Feijão, o Planalto Residual de São Carlos e o Planalto Centro Ocidental.

O Planalto Residual de São Carlos ocupa 40,6\% da bacia, circundando as bordas oeste, noroeste, norte e nordeste, distribuído numa faixa que pode variar entre 1,3 e 7km de largura em altitudes da ordem de 740 a 1.030m.

O Planalto Centro Ocidental ocorre na forma de um patamar intermediário em nível topográfico inferior, se comparado ao Planalto Residual de São Carlos, porém superior ao da Depressão Periférica Paulista posicionada à leste, fora do domínio da bacia. Distribui-se por 59,4\% da área, 
ocupando um eixo noroeste-sudoeste entre altitudes que variam de 680 a $740 \mathrm{~m}$, sendo que as vertentes apresentam declividades inferiores a $5 \%$.

O contato entre o Planalto Residual de São Carlos e o Planalto Centro Ocidental, em nível topográfico inferior, é marcado por vertentes escarpadas onde as declividades podem superar 30\% (Erro! Fonte de referência não encontrada.).

Figura 4 - Mapa geomorfológico da bacia hidrográfica do Ribeirão do Feijão.

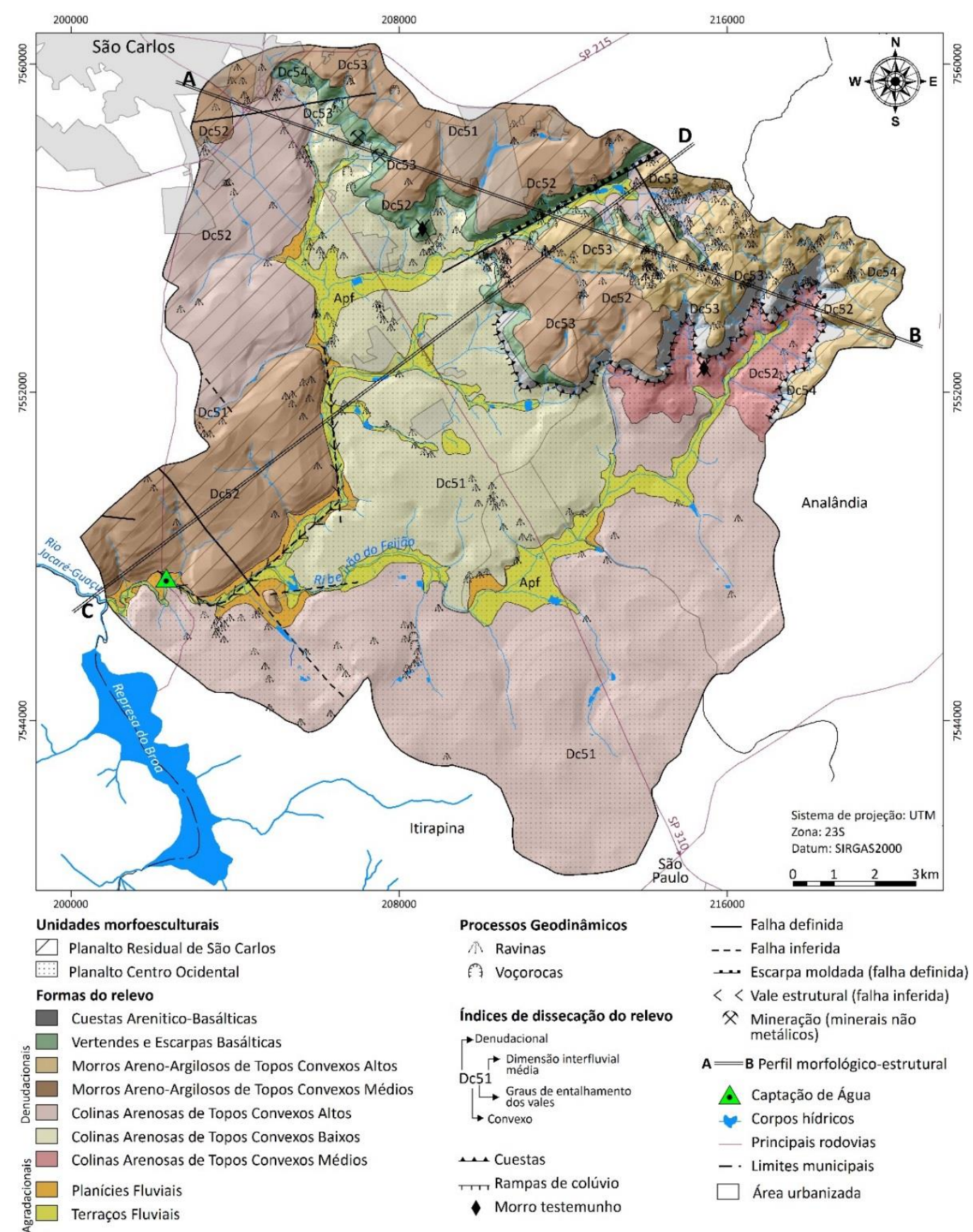

Fonte: Elaborada pelo autor.

Rev. Bras. de Cartografia, vol. 70, n. 4, outubro/dezembro, 2018. pp. 1257 - 1288. 


\subsection{Formas do Relevo}

O mapeamento geomorfológico da bacia hidrográfica do Ribeirão do Feijão, em escala 1:50.000, possibilitou identificar nove formas do relevo (Quadro ).

\subsubsection{Cuestas Arenitico-Basálticas}

As escapas cuestiformes ocorrem em altitudes da ordem de 830 a 960m. As declividades podem ser superiores a 60\%, expostas em vertentes abruptas voltados para o sul e para o oeste, flanqueando o bordo interior do Planalto Residual de São Carlos.

Seu front, delineado por paredões com alturas superiores a 100m, possuem caráter assimétrico, apresentando perfis horizontais divergentes alternados com convergentes nas reentrâncias, onde são abrigados ribeirões obsequentes. Os terrenos apresentam dimensão interfluvial que variam de Grande a Pequena e os vales possuem entalhamento Muito Forte (Dc52, Dc53, Dc54).

O modelado na forma de cuesta é resultante do processo erosivo diferencial em camadas litoestratigráficas distintas. Nas camadas superiores, as escarpas são recobertas pela Formação Itaqueri, na porção mediana, o contato se faz com os basaltos Formações Serra Geral superpostos a arenitos silicificados da Formação Botucatu, os quais completam a toposequência até a base (Erro! Fonte de referência não encontrada.).

A evolução dessas escarpas pode ser atribuída a dois processos principais: o morfogenético e o deposicional. Nas porções abruptas, dada a elevada declividade, predomina a morfogênese, enquanto que na porção basal, ocorrem depósitos cenozóicos na forma de rampas de colúvio. Essas rampas são lançadas do sopé das escarpas em direção às Colinas Arenosas de Topos Convexos Médios em nível topográfico inferior, demonstrando a maneira pela qual essas colinas foram criadas. 
Quadro 1 - Principais características geomorfológicas das unidades taxonômicas mapeadas.

\begin{tabular}{|c|c|c|c|c|c|c|c|c|c|c|c|c|c|c|c|}
\hline \multirow{3}{*}{$\begin{array}{c}1^{\circ} \text { Taxon } \\
\begin{array}{c}\text { Morfoes- } \\
\text { trutura }\end{array}\end{array}$} & \multirow{2}{*}{\multicolumn{2}{|c|}{$\frac{2^{\circ} \text { Taxon }}{\text { Morfoescultura }}$}} & \multirow{3}{*}{$\mid$\begin{tabular}{|c|}
$3^{\circ}$ Taxon \\
Unidades \\
morfológicas
\end{tabular}} & \multicolumn{2}{|l|}{$4^{\circ}$ Taxon } & \multirow{3}{*}{\begin{tabular}{|c|}
$5^{\circ}$ Taxon \\
$\begin{array}{c}\text { "Formas } \\
\text { de } \\
\text { terreno }\end{array}$ \\
\end{tabular}} & \multirow{3}{*}{\begin{tabular}{|c|}
$6^{\circ}$ Taxon \\
$\begin{array}{c}\text { Processos } \\
\text { geodinâmicos }\end{array}$ \\
\end{tabular}} & \multicolumn{4}{|c|}{ Meio físico } & $\begin{array}{l}\text { Meio biótico e } \\
\text { antrópico }\end{array}$ & \multicolumn{3}{|c|}{ Potenciais } \\
\hline & & & & \multirow{2}{*}{\multicolumn{2}{|c|}{ Formas do relevo }} & & & & & & & & & & Contaminação \\
\hline & Unidade & \begin{tabular}{|c|} 
Sub- \\
unidades
\end{tabular} & & & & & & $\begin{array}{c}\text { Decividace } \\
(\%)\end{array}$ & $\begin{array}{c}\text { Artm } \\
(\mathrm{m})\end{array}$ & Geologia & Solo & solo predominantes & $\begin{array}{l}\text { Escoamento } \\
\text { superficial }\end{array}$ & $\begin{array}{c}\text { Erosao } \\
\text { acelerada }\end{array}$ & $\begin{array}{l}\text { das águas } \\
\text { subterrâneas }\end{array}$ \\
\hline \multirow{9}{*}{$\begin{array}{l}\text { Bacia } \\
\text { sedimen- } \\
\text { tar do } \\
\text { Paraná }\end{array}$} & \multirow{9}{*}{\begin{tabular}{|l} 
Planalto \\
Ocidental \\
Paulista
\end{tabular}} & \multirow{5}{*}{$\begin{array}{l}\text { Planalto } \\
\text { Residual } \\
\text { de São } \\
\text { Carlos }\end{array}$} & \multirow{2}{*}{ Escarpas } & $\begin{array}{c}\text { Cuestas } \\
\text { Arenítico- } \\
\text { Basálticas } \\
\text { (Dc52, Dc53, } \\
\text { Dc54) }\end{array}$ & $\begin{array}{c}4,95 \\
\mathrm{Km}^{2} \\
2 \%\end{array}$ & $\begin{array}{l}\text { DX } \\
\text { CC } \\
\text { DC } \\
\text { CX }\end{array}$ & $\begin{array}{l}\text { Ravinas } \\
(11-2,9 \%) \\
\text { Voçoroca } \\
(1-5,3 \%)\end{array}$ & $\begin{array}{l}\text { Superior } \\
\text { a } 30 \%\end{array}$ & 830 a 960 & $\begin{array}{l}\text { Arenito da } \\
\text { Formação } \\
\text { Botucatu } \\
\text { silicificado }\end{array}$ & $\begin{array}{c}\text { Residual da Formação } \\
\text { Botucatu }\end{array}$ & $\begin{array}{l}\text { Floresta tropical } \\
\text { semidecídua } \\
\text { Pastagem }\end{array}$ & \multirow{2}{*}{$\begin{array}{l}\text { Baixo a } \\
\text { Médio }\end{array}$} & \multirow{2}{*}{$\begin{array}{l}\text { Baixo a } \\
\text { Médio }\end{array}$} & \multirow{2}{*}{ Muito baixo } \\
\hline & & & & \begin{tabular}{|c|} 
Vertentes e \\
Escarpas \\
Basálticas \\
(Dc52, Dc53, \\
Dc54) \\
\end{tabular} & $\begin{array}{r}7,28 \\
\mathrm{~km}^{2} \\
3 \%\end{array}$ & $\begin{array}{l}\mathrm{CC} \\
\mathrm{DX} \\
\mathrm{PX} \\
\mathrm{DC}\end{array}$ & $\begin{array}{l}\text { Ravinas } \\
(13-3,4 \%) \\
\text { Voçorocas } \\
(6-31,6 \%)\end{array}$ & $\begin{array}{l}\text { Superior } \\
\text { a } 20 \%\end{array}$ & 810 a 930 & $\begin{array}{c}\text { Fm Serra Geral e } \\
\text { intrusivas básicas } \\
\text { associadas }\end{array}$ & \begin{tabular}{|c|} 
Residuais das Fm \\
Serra Geral e Itaqueri, \\
Retrabalhado Arenoso \\
IV
\end{tabular} & $\begin{array}{l}\text { Floresta tropical } \\
\text { semidecídua, } \\
\text { Pastagem, Solo } \\
\text { exposto, Chácaras }\end{array}$ & & & \\
\hline & & & \multirow{2}{*}{ Morros } & \begin{tabular}{|c|} 
Morros Areno- \\
Argilosos de \\
Topos Convexos \\
Altos (Dc52, \\
Dc53, Dc54) \\
\end{tabular} & \begin{tabular}{|c|}
17,34 \\
$\mathrm{Km}^{2}$ \\
$7,13 \%$ \\
\end{tabular} & $\begin{array}{l}\text { DX } \\
\text { CC } \\
\text { CX } \\
\text { DR }\end{array}$ & \begin{tabular}{|c|} 
Ravinas \\
$(125-32,8 \%)$ \\
Voçorocas \\
$(4-21,1 \%)$
\end{tabular} & \begin{tabular}{|c|}
$<2 \%$ a \\
superiores \\
a $30 \%$
\end{tabular} & $860-1.030$ & \multirow{2}{*}{$\begin{array}{c}\text { Fm Serra Geral e } \\
\text { intrusivas básicas } \\
\text { associadas } \\
\text { Formação Itaqueri }\end{array}$} & \begin{tabular}{|c|c} 
Residuais das Fm \\
$\begin{array}{l}\text { Serra Geral e Itaqueri } \\
\text { Concreções lateríticas }\end{array}$ \\
\end{tabular} & $\begin{array}{l}\text { Floresta tropical, } \\
\text { semidecídua, } \\
\text { Pastagem, Cana e } \\
\text { Solo exposto }\end{array}$ & $\begin{array}{l}\text { Baixo a } \\
\text { Médio }\end{array}$ & \multirow[t]{2}{*}{ Médio } & \multirow[b]{2}{*}{$\begin{array}{l}\text { Médio a } \\
\text { Muito Alto }\end{array}$} \\
\hline & & & & \begin{tabular}{|c|} 
Morros Areno- \\
Argilosos de \\
Topos Convexos \\
Médios (Dc51, \\
Dc52, Dc53) \\
\end{tabular} & \begin{tabular}{|c|}
46,66 \\
$\mathrm{Km}^{2}$ \\
$19,2 \%$ \\
\end{tabular} & $\begin{array}{l}\text { DR } \\
\text { PR } \\
\text { CR } \\
\text { DX }\end{array}$ & $\begin{array}{c}\text { Ravinas } \\
(58-15,2 \%) \\
\text { Voçorocas } \\
(2-10,5 \%)\end{array}$ & 0 a $15 \%$ & 680-975 & & \begin{tabular}{|c|} 
Residuais das Fm. \\
Serra Geral e Itaqueri, \\
Retrabalhados Misto e \\
Arenoso III
\end{tabular} & $\begin{array}{l}\text { Cana, Pastagem } \\
\text { Floresta tropical } \\
\text { semidecídua, Solo } \\
\text { exposto, Chácaras }\end{array}$ & $\begin{array}{l}\text { Baixo a } \\
\text { Alto }\end{array}$ & & \\
\hline & & & \multirow{3}{*}{ Colinas } & \begin{tabular}{|c|} 
Colinas \\
Arenosas de \\
Topos Convexos \\
Altos (Dc51, \\
Dc52)
\end{tabular} & \begin{tabular}{|c|} 
\\
95,8 \\
$\mathrm{~km}^{2}$ \\
$39,4 \%$ \\
\end{tabular} & $\begin{array}{l}\mathrm{DR} \\
\mathrm{CR} \\
\mathrm{PR}\end{array}$ & $\begin{array}{c}\text { Ravinas } \\
(91-23,9 \%) \\
\text { Voçorocas } \\
(3-15,7 \%)\end{array}$ & \multirow[t]{2}{*}{0 a $10 \%$} & $680-850$ & \multirow{3}{*}{$\begin{array}{l}\text { Formação } \\
\text { Botucatu }\end{array}$} & $\begin{array}{c}\text { Residual da Fm } \\
\text { Botucatu } \\
\text { Retrabalhado } \\
\text { Arenoso I }\end{array}$ & $\begin{array}{l}\text { Pastagem, Cana, } \\
\text { Solo exposto, Cerrado } \\
\text { Silvicultura }\end{array}$ & \multirow{3}{*}{$\begin{array}{c}\text { Muito Baixo } \\
\text { a Baixo }\end{array}$} & \multirow{3}{*}{ Médio } & \multirow{3}{*}{$\begin{array}{l}\text { Médio a } \\
\text { Muito Alto }\end{array}$} \\
\hline & & \multirow{4}{*}{$\begin{array}{l}\text { Planalto } \\
\text { Centro } \\
\text { Ocidental }\end{array}$} & & \begin{tabular}{|c|} 
Colinas \\
Arenosas de \\
Topos Convexos \\
Baixos (Dc51, \\
Dc53) \\
\end{tabular} & 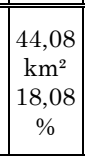 & $\begin{array}{l}\mathrm{DR} \\
\mathrm{CR} \\
\mathrm{PR}\end{array}$ & $\begin{array}{l}\text { Ravinas } \\
(57-15 \%) \\
\text { Voçorocas } \\
(2-10,5 \%)\end{array}$ & & $720-840$ & & $\begin{array}{c}\text { Residual da Fm } \\
\text { Botucatu } \\
\text { Retrabalhado } \\
\text { Arenoso I e IV }\end{array}$ & $\begin{array}{c}\text { Pastagem, } \\
\text { Silvicultura, } \\
\text { Cerrado, } \\
\text { Floresta tropical } \\
\text { semidecídua } \\
\end{array}$ & & & \\
\hline & & & & $\begin{array}{c}\text { Colinas } \\
\text { Arenosas de } \\
\text { Topos Convexos } \\
\text { Médios (Dc52, } \\
\text { Dc53) } \\
\end{array}$ & \begin{tabular}{|c|}
7,55 \\
$\mathrm{Km}^{2}$ \\
3,19 \\
$\%$ \\
\end{tabular} & $\begin{array}{l}\text { DR } \\
\text { CC } \\
\text { DC } \\
\text { CR }\end{array}$ & $\begin{array}{l}\text { Ravinas } \\
(7-1,8 \%) \\
\text { Voçoroca } \\
(1-5,3 \%)\end{array}$ & 0 a $15 \%$ & $780-850$ & & $\begin{array}{l}\text { Residual da Fm } \\
\text { Botucatu } \\
\text { Retrabalhados } \\
\text { Arenoso IV }\end{array}$ & $\begin{array}{c}\text { Citricultura, } \\
\text { Pastagem, Floresta } \\
\text { tropical semidecídua }\end{array}$ & & & \\
\hline & & & Agrada- & $\begin{array}{l}\text { Planícies } \\
\text { Fluviais (Apf) }\end{array}$ & \begin{tabular}{c|}
15,9 \\
$\mathrm{~km}^{2}$ \\
6,54 \\
$\%$ \\
\end{tabular} & Planares & $\begin{array}{c}\text { Ravinas } \\
(16-4,2 \%)\end{array}$ & 0 a $2 \%$ & 680 a 840 & $\begin{array}{l}\text { Fm Botucatu } \\
\text { Depósitos } \\
\text { aluvionares do } \\
\text { Quaternário }\end{array}$ & $\begin{array}{l}\text { Sedimentos aluvionares } \\
\text { oriundos das fm }\end{array}$ & $\begin{array}{c}\text { Campos úmidos } \\
\text { (Vegetação } \\
\text { herbácea), Mata de } \\
\text { galeria, Pastagem }\end{array}$ & Muito baixo & $\begin{array}{l}\text { Muito } \\
\text { Baixo }\end{array}$ & Muito Alto \\
\hline & & & & $\begin{array}{l}\text { Terraços } \\
\text { Fluviais } \\
\text { (Atf) }\end{array}$ & $\mid \begin{array}{c}3,6 \\
\mathrm{~km}^{2} \\
1,46 \%\end{array}$ & $\begin{array}{l}\mathrm{CC} \\
\mathrm{CR} \\
\mathrm{DR}\end{array}$ & $\begin{array}{l}\text { Ravinas } \\
(3-0,8 \%)\end{array}$ & & 680 a 760 & $\begin{array}{l}\text { Fm Botucatu, } \\
\text { depósitos } \\
\text { aluvionares }\end{array}$ & $\begin{array}{c}\text { Botucatu, Serra Geral e } \\
\text { Itaqueri. }\end{array}$ & \begin{tabular}{c|} 
Cana, Mata de \\
galeria, Pastagem, \\
Campos úmidos
\end{tabular} & $\begin{array}{c}\text { Muito baixo } \\
\text { a Baixo }\end{array}$ & $\begin{array}{l}\text { Baixo a } \\
\text { Médio }\end{array}$ & $\begin{array}{l}\text { Alto a Muito } \\
\text { Alto }\end{array}$ \\
\hline
\end{tabular}

Fonte: autor. ${ }^{*} \mathrm{CC}=$ Convergente Côncava, $\mathrm{CR}=$ Convergente Retilínea, $\mathrm{CX}=$ Convergente Convexa, PC=Planar Côncava, PR=Planar Retilínea,
DR=Divergente Retilínea, DX=Divergente Convexa. Fonte: Elaborada pelo autor.

Rev. Bras. de Cartografia, vol. 70, n. 4, outubro/dezembro, 2018. pp. 1257 - 1288. 
Figura 5 - Perfil morfológico-estrutural e níveis taxonômicos.

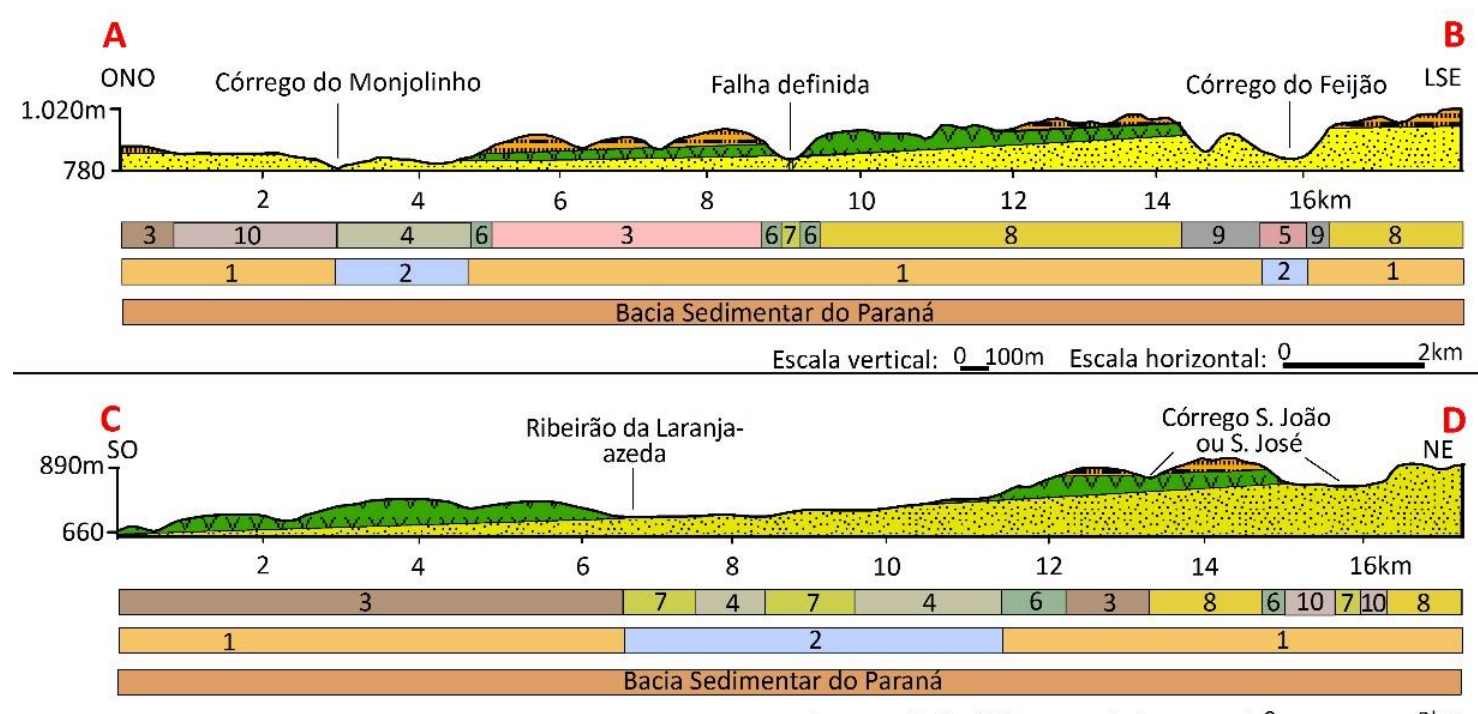

Escala vertical: $0 \underline{100 m}$ Escala horizontal: $0 \quad 2 \mathrm{~km}$

1 - Planalto Residual de São Carlos

2 - Planalto Centro Ocidental

3 - Morros Areno-Argilosos de Topos Convexos Médios

4 - Colinas Arenosas de Topos Convexos Baixos

5 - Colinas Arenosas de Topos Convexos Médios

6 - Vertentes e Escarpas Basálticas

7 - Planícies Fluviais

8 - Morros Areno-Argilosos de Topos Convexos Altos

9 - Cuestas Arenítico-Basálticas

10 - Colinas Arenosas de Topos Convexos Altos

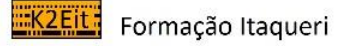

Ki jड़Kibt Formação Botucatu

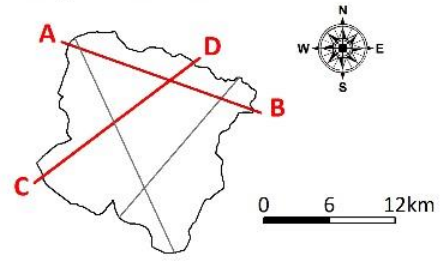

Fonte: Elaborada pelo autor.

As florestas tropicais semidecíduas ocupam de maneira adensada as rampas de colúvio das escarpas cuestiformes, e por vezes desde o seu topo, ocupando dominantemente seu front. No verão, tal fisionomia florestal recebe um acréscimo de umidade trazida pelos ventos sulinos provenientes do avanço da Massa Tropical Atlântica (mTa), que contribui para a formação de chuvas orográficas. No inverno, a Massa Polar Atlântica (mPa) provoca chuvas e decréscimo na temperatura.

A atividade humana que mais se adapta a este ambiente é a pastagem a qual pode ser implementada mesmo em altas declividades. Conforme apontado por Trimble e Mendel (1995), cabe ressaltar que o gado é um importante agente de mudança geomorfológica. $\mathrm{Na}$ área em apreço, a presença do gado contribui para o desequilíbrio do estado natural dos solos, 
compactando-os, reduzindo a infiltração, aumentando o escoamento de superfície e, consequentemente, acelerando os processos erosivos.

Costa (2017) salienta que dois fatores são determinantes para que essas áreas possuam um potencial Muito Baixo de contaminação das águas subterrâneas: i) nessa unidade aflora o Botucatu silicificado, e a presença da sílica altera a porosidade da rocha diminuindo a permeabilidade, ii) a presença de remanescentes de florestas tropicais semidecíduas em detrimento de atividades antrópicas potencialmente poluidoras.

\subsubsection{Vertentes e Escarpas Basálticas}

As colinas do Planalto Centro Ocidental, posicionadas em nível topográfico inferior, e os morros do Planalto Residual de São Carlos, em nível topográfico superior, ficam separados por uma faixa de relevo dominadas por Vertentes e Escarpas Basálticas (Erro! Fonte de referência não encontrada. - D).

Tal unidade de relevo ocorre entre classes altitudinais da ordem de 810 a 930m, onde são encontradas declividades que superam 20\%. A forma de terreno dominante é a convergente na perspectiva horizontal e côncava no perfil vertical, formando reentrâncias, seguido da forma divergente/convexa na porção frontal das vertentes. Tais formas das vertentes, estão intimamente relacionadas com o sistema de drenagem, o qual conta com vários canais de $1^{\mathrm{a}}$ e $2^{\mathrm{a}}$ ordem que promovem o dissecamento e a esculturação, conduzindo a diferentes intensidades de entalhe.

Ao norte da bacia, verifica-se que a drenagem orientada na direção oeste-sudoeste/leste-nordeste penetrou fundo no Planalto Residual de São Carlos desfazendo sua continuidade, provavelmente, concordante ao falhamento orientado na mesma posição. 
Figura 6 - Cuestas Arenítico-Basálticas (A), Colinas Arenosas de Topos Convexos Médios (B), Morros Areno-Argilosos de Topos Convexos Médios (C), Vertentes e Escarpas Basálticas com presença de voçoroca (D), Planícies Fluviais (E) e Colinas Arenosas de Topos Convexos Altos (F).

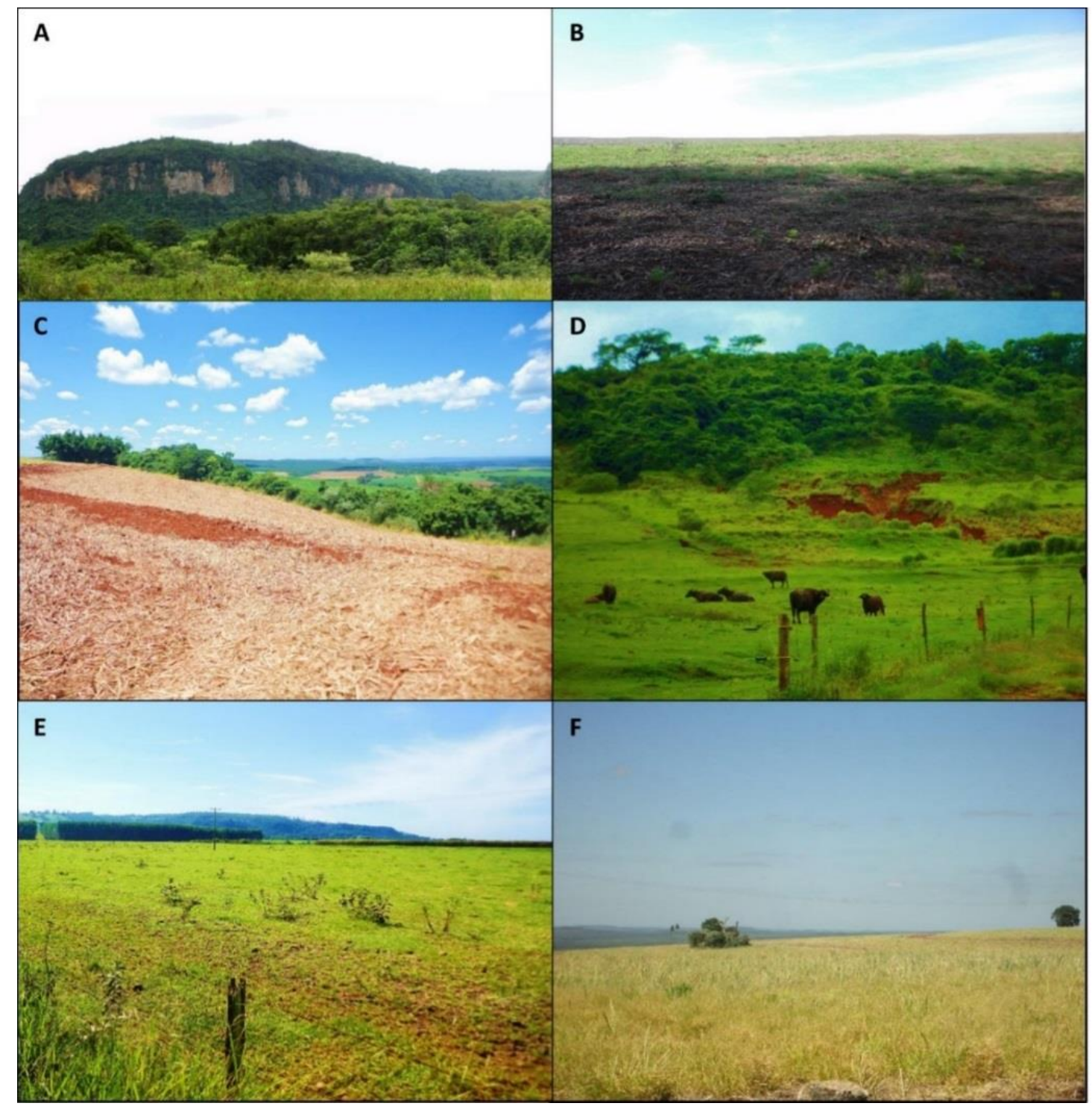

Fonte: Elaborada pelo autor.

O modelado apresenta dimensão interfluvial que variam de Grande a Pequena, sendo que os vales possuem entalhamento Muito Forte (Dc52, Dc53, Dc54). O solo superficial possui textura argilosa (Residual da Formação Serra Geral) com porcentagens variadas de areia oriundos dos sedimentos transportados da Formação Itaqueri à montante e Botucatu circundante, sendo observadas espessuras que variam entre 2 e 10m (Nishiyama, 1991). 
A vegetação que se desenvolve nestas áreas é a floresta tropical semidecídual em solos argilosos oriundos da decomposição de rochas eruptivas basálticas. O relevo acidentado é muito utilizado para fins de pastagem.

Quando o uso antrópico para fins de pastagem se faz presente, e, que por vezes ocupa áreas de solos mais arenosos e em declividades mais acentuadas, os processos geodinâmicos mais atuantes são as voçorocas, que se instalam em áreas onde o potencial de escoamento superficial e de erosão acelerada verificado é médio.

Com relação ao potencial de contaminação do aquífero Serra Geral (fraturado/livre) (COSTA, 2017) subjacente, as altas classes de declividades e a presença de solos argilosos não favorecem o fluxo vertical da água e a percolação de possíveis contaminantes.

\subsubsection{Morros Areno-Argilosos de Topos Convexos Altos}

A configuração do relevo, cujo os vales possuem dimensões interfluviais reduzidas (Dc53 e Dc54) se comparada com as demais formas de relevo encontradas na bacia, e o posicionamento altimétrico correspondentes às áreas mais elevadas, ocupando o reverso das cuestas (860 a 1.030m), condicionaram a individualização dessa forma de relevo.

As formas de terreno são dominadas pelo formato divergente convexo (horizontal/vertical), seguido do formato convergente côncavo, distribuídas em uma sucessão não uniforme de morros ondulados esculpidos nos sedimentos da Formação Itaqueri. As declividades variam entre inferiores a $2 \%$ e maiores que $30 \%$. As menores declividades estão nos fundos de vale e as maiores nas vertentes, principalmente as que fazem a transição entre essa forma de relevo e as escarpas cuestiformes.

O domínio da Formação Itaqueri cujo solos residuais são de textura arenosa, associado a áreas de altas declividades, formas de terrenos convexadas e uso do solo relacionados a pastagem, cana-de-açúcar e ao solo 
exposto (em preparo para o cultivo da cana), compõem um cenário que favorece a deflagração de processos geodinâmicos, resultando em mais de $30 \%$ dos ravinamentos e $15 \%$ das voçorocas encontradas na bacia.

Como consequência, as nascentes tornam-se vulneráveis ao assoreamento em função dos numerosos processos erosivos acelerados verificados na área.

\subsubsection{Morros Areno-Argilosos de Topos Convexos Médios}

Ocorrem na borda oeste da bacia, onde são sustentados pela Formação Serra Geral (975m), encontrando-se truncado por falhas próximas à sua porção basal, no contato com os arenitos da Formação Botucatu (680m). Na região norte e central, sua gênese está associada aos arenitos da Formação Itaqueri.

O relevo denudacional é constituído por morros de topos convexos de dimensões interfluviais Médias a Muito Grandes, com vales de entalhamento Muito Forte (Dc51, Dc52 e Dc53). As declividades alcançam 15\%, distribuídas em encostas com perfis horizontais divergentes e verticais retilíneos.

Os mantos de alteração sofreram desgaste erosivo em função das diferenças litológicas, originando solos de composição mineralógica mais argilosa, oriundos da Formação Serra Geral, e arenosos provenientes da Formação Itaqueri.

Diante dessas condicionantes físicas, esta forma do relevo apresenta variação quanto ao escoamento superficial, variando de Baixo a Alto, e Médio potencial com relação ao desenvolvimento de processos erosivos acelerados. Muitos dos processos geodinâmicos identificados estão relacionados ao desmatamento e a não adoção de medidas preventivas quando o solo encontrase exposto para o preparo do cultivo da cana e para a pastagem.

O potencial de contaminação das águas subterrâneas (Médio a Muito Alto) está relacionado principalmente a presença do aquífero Itaqueri (intergranular e livre) associado ao cultivo da cana-de-açúcar. Segundo 
Spadotto et al. (2004), a cana e os citrus fazem o uso frequente, e muitas vezes incorreto, de agroquímicos e são fontes potenciais de contaminação.

\subsubsection{Colinas Arenosas de Topos Convexos Altos}

Essa forma de relevo ocorre em níveis altimétricos da ordem de $840 \mathrm{~m}$. A partir dessa altitude, as vertentes tendem a ter um formato alongado, estendendo-se em direção as planícies fluviais a $680 \mathrm{~m}$.

O relevo denudacional apresenta topos convexizados de dimensões interfluviais Grande a Muito Grande e grau de entalhamento dos vales Muito Forte (Dc51, Dc52) dispostos em vertentes com declividades da ordem de 0 a $10 \%$.

Os solos residuais da Formação Botucatu recobrem esta unidade, apresentando espessuras que podem chegar a 20m (Nishiyama, 1991).

A associação entre solos arenosos, baixas declividades e altos coeficientes de permeabilidade (entre $10^{-3}$ e $10^{-2} \mathrm{~cm} / \mathrm{s}$ ) determina baixos índices de escoamento superficial. Tal configuração do meio físico mediante a presença da cana, favorece a infiltração da água e de possíveis contaminantes, elevando o potencial de contaminação do aquífero Botucatu.

Não obstante, a presença da pastagem aumenta o potencial de deflagração dos processos erosivos acelerados como os ravinamentos.

\subsubsection{Colinas Arenosas de Topos Convexos Baixos}

Este compartimento é caracterizado pela intensa dissecação do relevo, verificado pela baixa altimetria $(720$ a $840 \mathrm{~m})$, e a presença de colinas que exibem topos convexizados e suavizados, cuja as declividades não ultrapassam $10 \%$.

Influenciados pela Formação Botucatu subjacente, esses plainos de erosão apresentam dimensão interfluvial Muito Grande a Média (cabeceiras) e grau de entalhamento dos vales Muito Forte (Dc51). 
Os solos residuais são profundos e bem drenados, fazendo com que o escoamento de superfície não seja favorecido e sim o de infiltração da água, fazendo com que os aquíferos sejam abundantemente recarregados.

Por outro lado, tais características físicas facilitam que possíveis fluídos contaminantes atinjam o manancial subterrâneo, demonstrado no alto potencial de contaminação das águas subterrâneas.

A atividade humana predominante é a silvicultura, seguida da pastagem, neste caso, a presença do gado é um potencial deflagrador das ravinas. Verifica-se também a presença de áreas de Cerrado (sensu stricto) e regenerados que se desenvolveram em áreas outrora ocupadas com atividades agropecuárias.

\subsubsection{Colinas Arenosas de Topos Convexos Médios}

Situa-se na porção nordeste da bacia, em altitudes intermediárias (780 a $850 \mathrm{~m}$ ) o que caracteriza essa unidade do relevo como de transição entre as Cuestas Arenítico-Basálticas e as Colinas Arenosas de Topos Alongados, na porção mais baixa.

O relevo denudacional procedente da Formação Botucatu gerou vales com dimensões interfluviais de Grande a Média e graus de entalhamento Muito Forte (Dc52 e Dc53). É possível verificar a presença de um morro testemunho, encontrando-se ladeado por rampas de colúvio de material arenoso.

O escoamento de superfície se mostra baixo em função dos solos arenosos dispostos em vertentes com baixas declividades (<15\%) e a presença de áreas florestadas. No entanto, o potencial de erosão acelerada aumenta principalmente em áreas de pastagem.

A presença da citricultura faz com que essas áreas possuam de Médio a Alto potencial de contaminação de aquíferos.

\subsubsection{Planícies Fluviais (Apf)}


Ocorrem de maneira alongada e por vezes alargada no interior da bacia, ocupando baixios sujeitos à inundações periódicas e fundo de vales dos principais cursos d'água. As dimensões interfluviais são amplas (superior a $1.500 \mathrm{~m}$ ), escoando uma rede de drenagem pouco encaixada, interposta entre matas de galeria e prados úmidos.

Geneticamente, são representadas por camadas superficiais pouco desenvolvidas $(<1 \mathrm{~m})$, constituídas por sedimentos não consolidados de textura arenosa e presença acentuada de matéria orgânica.

Em virtude de sua topografia deprimida associada à baixa declividade $(<2 \%)$, o escoamento superficial não é favorecido, e sim a acumulação de água e sedimentos. Nessas planícies pode ser constatada a presença da água quase que superficialmente, mantendo sempre verde uma vegetação de fisionomia predominantemente herbácea, que é muito utilizada para fins de pastagem.

Verifica-se nessas planícies fluviais a presença de ravinamentos dominantemente relacionados ao gado, o qual pisoteia, principalmente à procura de água para dessendentação deflagrando a erosão.

O potencial Muito Alto de contaminação das águas subterrâneas se remete a presença do aquífero Aluvionar, o qual aflora. Essas planícies não possuem a capacidade de retardamento e de depuração de uma possível carga de contaminante aplicada na superfície, pelo contrário, favorece o contato dos poluentes com as águas subterrâneas mais profundas, entre eles o Aquífero Botucatu subjacente.

\subsubsection{Terraços Fluviais}

Individualizam-se das planícies fluviais por apresentarem morfologia em nível topográfico ligeiramente mais elevado, sob a forma de lombas muito suaves posicionadas nos flancos de vales de dimensões Muito Grandes (superior a $1.500 \mathrm{~m}$ ). 
Nestes patamares é possível verificar formas de terreno dominantemente retilíneas. Na região próxima a confluência entre o Ribeirão Laranja-azeda e o Ribeirão do Feijão, esses depósitos ocorrem de forma mais alargada, provavelmente motivados pelas paleomigrações laterais do canal. Nas proximidades da capitação de água, a acreção lateral é favorecida pela baixa velocidade do fluxo e tendência meandriforme do baixo curso do Ribeirão do Feijão.

Os depósitos de sedimentos não consolidados possuem ampla diversidade textural. Na borda sudoeste da bacia, junto a um vale estrutural moldado por falhas, é constituído de materiais finos oriundos de da Formação Serra Geral. Na região central da bacia é constituído por sedimentos arenosos.

A sua morfologia permite que sejam desenvolvidas atividades como o cultivo da cana e a pecuária nos trechos enxutos de planície. Em função disto, apresentam um incremento nos potenciais de escoamento superficial e de erosão acelerada.

Já o potencial de contaminação das águas subterrâneas tende a diminuir se comparado às planícies fluviais, pois o contato hidráulico com o aquífero aluvionar não se faz próximo a superfície.

\section{Conclusões}

O posicionamento dos processos geodinâmicos reflete pontos de maior alteração das condições morfogênicas naturais na bacia. O maior número destes processos, está localizado sob domínio dos Morros Areno-Argilosos de Topos Convexos Altos, posicionado no reverso das cuestas em regiões de maiores declividades e solos de matriz areno-argilosa oriundos da Formação Itaqueri.

É nesta forma do relevo que está concentrado o maior número de nascentes.

A deflagração dos processos erosivos acelerados, apresenta relação direta com remoção da cobertura vegetal natural e implantação de atividades 
humanas em solos com matriz arenosa. O manejo inadequado da bovinocultura, seguido ao da cana-de-açúcar, são as principais ações antrópicas que deflagram esses processos. Consequentemente há um incremento da carga de sedimentos carreada para os corpos hídricos e gerando assoreamento das áreas de nascentes e das planícies fluviais.

Em função das alterações nas condições naturais de infiltração e de escoamento superficial da água, provocadas pelo uso antrópico do solo, um grande volume de água pode deixar de infiltrar na bacia e recarregar aquíferos e nascentes, reduzindo a disponibilidade hídrica para o consumo humano e para os sistemas ecológicos.

No manancial do Ribeirão do Feijão, as áreas de recuperação florestal devem estar relacionadas a região nordeste da bacia hidrográfica, onde se localizam grande parte dos processos geodinâmicos e nascentes. A recarga das águas subterrâneas é intensificada nos domínios das Colinas Arenosas de Topos Convexos e Baixos, por estarem posicionadas em regiões topograficamente deprimidas e em função de condicionantes geotécnicos, como a matriz arenosa das formações geológicas e solos correspondentes. Nessas áreas de elevada capacidade de infiltração, devem ser desencorajados culturas que fazem o uso de agroquímicos a fim de evitar a percolação de possíveis contaminantes.

É importante destacar aqui a contribuição singular que possui a cartografia geomorfológica quando aplicada aos estudos do meio-físico natural, sob intervenção ou não das atividades do homem, por apresentar documentos que integram informações estáticas e dinâmicas. Aliada a ela, a compartimentação das formas de relevo é tarefa mais que necessária àqueles que se lançam ao entendimento dos processos atuantes sobre a superfície

Dessa forma, a apresentação detalhada das informações geomorfológicas, quanto à definição dos níveis taxonômicos com maior apuramento de processos identificados no mapeamento geomorfológico, permite melhor subsídio na identificação de potencialidades e fragilidades da área. 


\section{Agradecimentos}

A Coordenação de Aperfeiçoamento de Pessoal de Nível Superior (CAPES), pela concessão da bolsa de estudo durante a realização da pesquisa e ao discente Gustavo Clementino Santos (Laboratório de Geotecnologias Departamento de Engenharia Civil - Universidade Federal do Rio Grande do Norte), por formatar a versão final do artigo.

\section{Referências}

AB'SÁBER, A. N. A geomorfologia do Estado de São Paulo. In: CONSELHO NACIONAL DE GEOGRAFIA. Rio de Janeiro, IBGE, 1994, pp. 1-97.

AB'SÁBER, A. N. Os domínios de natureza do Brasil: potencialidades paisagísticas. 2. ed. São Paulo: Ateliê Editorial, 2003. 151p.

AB'SÁBER, A. N. Regiões de circundesnudação pós-cretácea, no Planalto Brasileiro. Boletim Paulista de Geografia, São Paulo, v. 1, 1949, pp. 1-21.

ALMEIDA, F. F. M. Fundamentos Geológicos do Relevo Paulista. Boletim do

Instituto Geográfico e Geológico do Estado de São Paulo, v. 41, 1964. pp. 169-263.

BISHOP, M. P., JAMES, L. A., SHRODER JR., J. F. e WALSH, S. J. Geospatial technologies and digital geomorphological mapping: Concepts, issues and research. Geomorphology, v. 137, n. 1, 2012. pp. 5-26.

CASTALDI, F., CHIOCCHINI, H. Effects of land use changes on badland erosion in clayey drainage basins, Radicofani, Central Italy. Geomorphology. v. 169170, 2012, pp. 98-108.

CERMINARO, A. C. e OLIVEIRA D. Relações Solo-Relevo Através da Compartimentação Geomorfológica da Bacia Hidrográfica do Ribeirão Feijão, nos Municípios de São Carlos, Analândia e Itirapina no Estado de São PauloBR: Ordenações de Unidades para Uso e Ocupação Adequados. Rev. Bras. de Geog. Física, v. 8, n. 2, 2015, pp. 352-364.

CHRISTOFOLETTI, A. Geomorfologia. São Paulo: EDIUSP, 1974. 149 p. 
COMPANHIA DE PESQUISA DE RECURSOS MINERAIS (CPRM). Mapa Geológico do Estado de São Paulo, 2006, Escala 1:750.000.

COSTA, C. W. Mapeamentos geoambientais, em escala 1:50.000, aplicados em análises de planejamento territorial de manancial periurbano: bacia do Ribeirão do Feijão, São Carlos, SP. 2017. 166 f. Tese (Doutorado em Ciências Ambientais). Universidade Federal de São Carlos, São Carlos, SP.

COSTA, C. W., DUPAS, F. A., CESPEDES, J. G., SILVA, L. F. Monitoramento da expansão urbana, cenários futuros de crescimento populacional e o consumo de recursos hídricos na cidade de São Carlos, SP. Geociências, v. 32, n. 1, 2013, pp. $63-80$.

DEPARTAMENTO DE ÁGUAS E ENERGIA ELÉTRICA DO ESTADO DE SÃO PAULO (DAEE). Estudo de águas subterrâneas, região administrativa 6: Ribeirão Preto, São Paulo, São Paulo: DAEE. 1974. 4v.

ESRI. ArcGIS for the desktop 10.4.1, 2016.

ESRI. World_Imagery. Source: Esri, DigitalGlobe, GeoEye, i-cubed, USDA, USGS, AEX, Getmapping, Aerogrid, IGN, IGP, swisstopo, and the GIS User Community 2011.

Fundação Sistema Estadual de Análise de Dados (SEADE). Informações dos

Municípios Paulistas. Site: < http://www.imp.seade.gov.br/frontend/\#/tabelas>. Acessado em agosto de 2017. INSTITUTO BRASILEIRO DE GEOGRAFIA E ESTATÍSTICA (IBGE). Folha Topográfica de Corumbataí (SF-23-Y-A-I-2), Folha Topográfica de São Carlos (SF-23-Y-A-I-1), 1971, Escala 1:50.000.

INSTITUTO BRASILEIRO DE GEOGRAFIA E ESTATÍSTICA (IBGE). Resolução $N^{0}$ 1/2005. Estabelece o Sistema de Referência Geocêntrico para as Américas (SIRGAS). Brasília, 2005.

INSTITUTO DE PESQUISAS TECNOLÓGICAS DO ESTADO DE SÃO PAULO (IPT). Determinação de áreas críticas à erosão ao longo das faixas marginais dos reservatórios dos rios Tietê e Paranapanema. Relatório 26.769, 1989.

INSTITUTO GEOLÓGICO DE SÃO PAULO (IG). Folha Geológica de Corumbataí. São Paulo. 1984. Escala 1:50.000. 
INSTITUTO NACIONAL DE PESQUISAS ESPACIAIS (INPE). TOPODATA, banco de dados geomorfométricos do Brasil. Site: http://www.dsr.inpe.br/topodata/index.php. Acessado em: junho de 2017.

IRITANI, M. A.; EZAKI, S. As águas subterrâneas do Estado de São Paulo. 3. ed. São Paulo: Secretaria de Estado do Meio Ambiente - SMA, 2012. 104 p.

MILANI, E. J.; MELO, J. H. G. de; SOUZA, P. A.; de; FERNANDES, L. A; FRANÇA. A. B. Bacia do Paraná. Bol. Geociências. Petrobras, Rio de Janeiro, v. 15, n. 2, 2007, pp. 265-287.

NISHIYAMA, L. Mapeamento geotécnico preliminar da quadrícula de São Carlos - SP. 1991. 228 f. Dissertação (Mestrado em Geotecnia). Escola de Engenharia de São Carlos. USP, 1991.

OLIVEIRA, J. B.; PRADO, H. Levantamento pedológico semidetalhado do estado de São Paulo: quadrícula de São Carlos. II. Memorial descritivo. Campinas: IAC. 1984. 188 p.

PARAGUASSU, A. B. Experimental silicification of sandstone. Geological Society of America Bulletin, v. 83, n. 9, 1972, pp. 2853-2858.

PONÇANO, W. L.; CARNEIRO, C. D. R.; BISTRICHI, C. A.; ALMEIDA, F. F. M. de; PRANDINI, F.L. Mapa Geomorfológico do Estado de São Paulo, Mapa 1:1.000.000 e nota explicativa; Série Monografias, IPT, SP, 1981.

PORTILLO, E. Z. F. (1988). Considerações sobre a caracterização tecnológica, a explotação e os usos do arenito Botucatu silicificado na região de São Carlos - SP. 1988. 85 f. Dissertação (Mestrado em Geotecnia). Escola de Engenharia de São Carlos, USP, 1988

ROSS, J. (Org.). Ecogeografia do Brasil. Subsídios para planejamento ambiental. São Paulo: Oficina de Textos, 2006. 208 p.

ROSS, J. L. S. e MOROZ, I. C. Mapa Geomorfológico do Estado de São Paulo. Depto Geografia - FFLCH - USP / IPT / FAPESP, SP, 1997. 1997. Escala 1:500.000.

ROSS, J. L. S. O registro cartográfico dos fatos geomorfológicos e a questão da taxonomia do relevo. Revista do Departamento de Geografia. São Paulo, Edusp. n. 6, 1992, pp. 17-30.

ROSS, J. L.S. Relevo Brasileiro: uma nova proposta de classificação. Revista do Departamento de Geografia, v. 4, 1985. 
SÃO CARLOS. Lei N 13.944/2006 - Dispõe sobre a criação da Lei de Proteção e Recuperação dos Mananciais do Município - APREM.

SOARES, J. J.; SILVA, D. W.; LIMA, M. I. S. Current State and projection of the probable original vegetation of the São Carlos region of São Paulo State, Brazil. Brazilian Journal of Biology, n. 63, v. 3, 2003, pp. 527-536.

SPADOTTO, C. A.; GOMES, M. A. F.; LUCHINI, L. C.; ANDRÉA, M. M. Monitoramento do risco ambiental de agrotóxicos: princípios e recomendações. Embrapa Meio Ambiente. Documentos 42, Jaquariúna, SP, 2004,29 p.

STRAHLER, A. N. Hypsometric (area-altitude) analysis of erosional topography.

Geological Society of America Bulletin, v. 63, n. 11, p. 1117-1142, 1952.

TOLENTINO, M. Estudo crítico sobre o clima da região de São Carlos. São Carlos: EdUFscar. 2007, 76 p.

TRIMBLE, S. W.; MENDEL, A. C. The cow as a geomorphic agent A critical review. Geomorphology, v. 13, 1995, pp. 233-253.

ZUQUETTE, L. V. Mapeamento geotécnico preliminar na região de São Carlos. 1981. 86 f. Dissertação (Mestrado em Geotecnia). Escola de Engenharia de São Carlos. USP, 1981. 